Scientiæ studia, São Paulo, v. 9, n. 3, p. 563-83, 2011

\title{
ist \\ Máquinas petrificadas: Max Weber e a sociologia da técnica
}

\author{
Carlos Eduardo SELL
}

\begin{abstract}
茴
RESUMO

Qual é o lugar da técnica no pensamento de Max Weber? A partir do exame das categorias de técnica, ação técnica e racionalidade técnica, o artigo busca demonstrar que a reflexão weberiana sobre o âmbito técnico move-se em uma dupla dimensão. Em um primeiro plano trata-se da compreensão da especificidade da técnica enquanto fenômeno social e, em um plano mais amplo, envolve também o entendimento do papel da tecnociência na modernidade. Neste duplo registro, Weber analisou a racionalização da maquinaria no contexto de surgimento da era moderna e, ao mesmo tempo, descreveu o processo de racionalização cultural como um amplo processo de tecnificação da ação e de predomínio da racionalidade técnica sobre o conjunto da vida social.
\end{abstract}

Palavras-chave • Weber. Técnica. Racionalidade. Racionalização. Modernidade técnica.

\section{INTRODUÇÃO}

Max Weber foi, dentre os autores da geração fundadora da sociologia, um dos teóricos com maior capacidade para abarcar em sua reflexão as mais diferentes áreas da vida social. Nos seus múltiplos escritos, ele trata de temas tão distantes como a música e as relações agrárias, as condições psicofísicas do trabalho e as bases do imperialismo, o papel da ciência no mundo moderno e as origens do capitalismo, o papel dos profetas e dos mercados, e assim por diante. Mesmo se restringimos nossa atenção a apenas um único de seus escritos, como a obra póstuma Economia e sociedade, somos confrontados novamente com a enorme erudição de Weber, condição que lhe permitia dissertar com profundidade e maestria sobre assuntos complexos como a metodologia, a economia, a política, o direito, a religião, a estratificação social, a nacionalidade, as cidades e os grupos sociais.

Todavia, dentre os capítulos da sociologia weberiana que menos têm merecido a atenção dos pesquisadores, encontra-se o tema da técnica. Sabemos que não há nenhuma obra de Weber dedicada especificamente a esse tema e, de forma geral, suas reflexões sobre o assunto acham-se dispersas e fragmentadas nos mais diferentes lugares 
de seus escritos. De qualquer forma, mesmo um assunto aparentemente tão especializado como a sociologia da técnica não é uma lacuna no pensamento weberiano e, se formos consultar a sua obra, verificaremos que ele se dedica a analisar o papel da técnica nos mais diversos contextos, passando em revista desde as técnicas de oração mística e ascética, englobando ainda observações sobre as técnicas de produção econômica, elaboração sistemática do direito e, até, de condução global da vida.

Apesar do caráter múltiplo, disperso e mesmo difuso das observações e reflexões de Weber sobre a técnica, a relevância da questão não escapou aos seus estudiosos mais atentos, a tal ponto que um especialista do porte de Julien Freund (cf. 1987, p. 196201) não deixou que faltasse em seu estudo um tópico dedicado à sociologia weberiana da técnica. Aliás, sobre esse assunto, Freund nos adverte que seria um erro considerar a técnica como apenas um assunto secundário ou marginal do pensamento weberiano.

Causou muitas vezes admiração o fato de Weber não ter dedicado um estudo ou uma obra especial ao problema da técnica. Seria, entretanto, um erro considerar essa lacuna como fraqueza de seu pensamento. Ao contrário, a evolução e as consequências do fenômeno técnico acham-se invocadas e analisadas em quase todas as suas obras, pois constituem um dos fatores determinantes da racionalização crescente das sociedades, e isso em todos os domínios, tanto nos da economia como nos da religião e da arte (Freund, 1987, p. 201).

Desse modo não é surpresa que a importância da reflexão weberiana sobre a técnica tenha ido além do estreito círculo dos peritos nesse pensador e seja mencionada em varias coleções que discorrem sobre o assunto, como é o caso, em especial, da coleção "Que sais-je?”, importante veículo de divulgação especializada, em que Jean-Yves Goffi (1988, p. 21-2), ao apresentar A Filosofia da técnica, foi buscar exatamente em Max Weber sua definição para o fenômeno: "a técnica de uma atividade é em nosso espírito a soma dos meios necessários para seu exercício, por oposição ao sentido ou ao fim da atividade que lhe determina (concretamente falando), em última análise, a orientação". Esses testemunhos já seriam fundamento suficiente para a tarefa de legitimação da possibilidade e importância de uma reconstrução da "sociologia weberiana da técnica". Caminhando nessa direção, este artigo busca reconstruir o pensamento de Weber sobre o tópico servindo-se tanto de seus escritos (método exegético-hermenêutico) quanto das premissas globais de seu pensamento (método lógico-sistemático). Porém, mais do que uma descrição da teoria weberiana buscarei aproximar sua reflexão do conceito de "modernidade técnica" (cf. Brüseke, 2002), ampliando, assim, o alcance de meu exercício. Dessa forma, malgrado sua pequena densidade quan- 
titativa, desejo demonstrar que uma releitura sistemática permite-nos afirmar que a questão da técnica revela-se uma questão central no pensamento de Max Weber e uma das linhas fundamentais de sua compreensão da época moderna. Entendo, pois, que o predomínio da técnica pode ser compreendido como um dos elementos que definem o sentido do moderno, e é por apontar nessa direção que podemos ver, em Weber, um importante precursor da sociologia da modernidade técnica.

\section{A TÉCNICA}

As considerações de caráter teórico mais significativas que Weber faz a respeito da técnica encontram-se no segundo capítulo de Economia e sociedade. Nessa obra, o autor situa o tema da técnica no contexto da vida econômica, o que não significa que ela diga respeito apenas a essa dimensão da vida social. Pelo contrário, Weber se preocupa em diferenciar claramente o âmbito da técnica do âmbito econômico. Em suas palavras, "a ‘técnica' de uma ação significa a soma dos meios nela empregados, em oposição ao sentido ou fim pelo qual, em última instância, ela se orienta (in concreto)" (Weber, 1994, p. 38). Formulado dessa maneira, o conceito de técnica acaba presente em qualquer esfera de atividade humana, pois em todas elas são empregados meios. A conclusão é formulada expressamente pelo próprio autor: "a técnica, nesse sentido, existe, portanto, em toda ação: técnica da oração, técnica da ascese, técnica do pensamento e da pesquisa, técnica mnemônica, técnica da educação, técnica da dominação política ou hierocrática, técnica administrativa, técnica erótica, técnica militar, técnica musical (de um virtuoso, por exemplo), técnica de um escultor ou pintor, técnica jurídica" (p. 38).

Dada a definição, em que medida a técnica se diferencia da economia? Na visão weberiana, "a economia orienta-se, em primeiro lugar, pelo fim aplicado; a técnica, pelo problema dos meios a serem aplicados (dado o fim)" (p. 39). Tal concepção pode ser esclarecida com um exemplo fornecido pelo próprio Weber. Um problema técnico seria quais são os dispositivos que deveriam ser aplicados para extrair produtos de minas de uma determinada profundidade. Todavia, a questão passa ao registro da ação econômica quando a pergunta reside sobre a finalidade daquela ação, ou seja, se ela será empregada em uma economia de troca (visando o lucro) ou em uma economia planejada (visando a satisfação de necessidades coletivas). Quando traduzida para o âmbito econômico, a técnica reveste-se de conotação específica e os meios técnicos empregados passam a ser traduzidos na linguagem sistêmica da economia através da ideia de custos: "do ponto de vista da 'gestão econômica', os problemas 'técnicos' significam o exame dos "custos" ( p. 39). 
Estabelecida a diferença entre a esfera econômica e a esfera técnica, no passo seguinte, Weber esclarece ainda qual é a relação entre elas. Sobre esse tema, ele não postulava (como certas versões deterministas do marxismo) que a economia é a única esfera que responde pelo desenvolvimento tecnológico. Em sua visão "a orientação econômica do chamado desenvolvimento tecnológico pelas possibilidades de lucro é um dos fatos fundamentais da história da técnica. Mas não foi exclusivamente essa orientação econômica, por mais importante que tenha sido, que indicou à técnica o caminho de seu desenvolvimento" (Weber, 1994, p. 39). Partindo de sua epistemologia multicausal, Weber sustenta que outros fatores também podem ser determinantes no processo: "houve também, em parte, o jogo de ideias e a mediação de ideólogos 'alheios ao mundo', em parte, interesses fantásticos ou dirigidos ao além, em parte, problemas artísticos e outros motivos extra-econômicos" (p. 39); o que não quer dizer que o pensador negue a importância dos fatores econômicos que, com certeza, são vitais para entender o desenvolvimento tecnológico. Sobre esse ponto ele é muito enfático e afirma que

em todos os tempos e especialmente hoje, o fator principal para o desenvolvimento técnico é o condicionamento econômico; sem o cálculo racional como base da economia, isto é, sem as condições histórico-econômicas de natureza extremamente concreta, não teria nascido a técnica racional (p. 29-30).

Examinada nos seus pressupostos lógicos, resulta claro que a definição weberiana de técnica emprega dois conceitos-chave para sua elaboração: as categorias de meio (Mittel) e de fim ou objetivo (Zweck). Ao empregá-las, Weber utiliza o "objetivo" como polo negativo (ou seja, o âmbito técnico define-se por uma relação de oposição ao fim), embora ele seja fundamental na definição, pois representa o contexto maior sem o qual a ideia de técnica não se explica (porque o problema da utilização dos meios só se coloca em função dos objetivos a serem atingidos). No entanto, é a categoria de "meio" que constitui o elemento positivo, ou seja, é nesse aspecto que repousa a natureza exclusiva e própria da técnica. Weber não identifica técnica com "tecnologia", ou seja, com o conjunto dos instrumentos, objetos, aparelhos e máquinas. Sua reflexão remete o conceito de técnica ao âmbito do instrumental com o qual ele, na prática, se identifica. A "tecnicidade" em Weber significa, pois, "instrumentalidade" e é nesse contexto que os sistemas técnicos ganham sentido. 


\section{A AÇÃo TÉGNICA}

A reflexão weberiana sobre a técnica não se move apenas no âmbito lógico ou categorial. Seu contexto hermenêutico é a reflexão sociológica e, por isso, o pensar de Weber sobre a instrumentalidade só ganha seu pleno sentido quando situada no contexto da vida social. Nessa direção, é outra dimensão do conceito weberiano de técnica que ganha relevo, a saber, sua dimensão antropológica. Consoante o pensamento do autor, o ponto de partida da análise sociológica é o sentido que os indivíduos conferem a suas ações na sociedade. Ao aceitar essa premissa, a dimensão antropológica do conceito weberiano de técnica liga-se, necessariamente, ao conceito de ação social. Nesse contexto cabe, portanto, a seguinte pergunta: é possível localizar em Weber a noção de que a técnica seria uma formação de ação social? Ou, colocando em outros termos, o que significa a ação (social) técnica? Ou ainda, quais são as propriedades do agir técnico?

O exame atento do conceito de técnica, acima apresentado, revela que ela representa um elemento presente em cada ação social, mas, em si mesma, ela não é uma forma diferenciada de agir. De fato, Weber contemplou essa possibilidade apenas de forma indireta, ao dizer que

o sentido último de uma ação concreta, considerado dentro de um complexo de ações pode ser de natureza "técnica", isto é, constituir um meio em relação àquele complexo; mas, em relação à ação concreta, essa função técnica (técnica do ponto de vista daquele complexo de ações) constitui o "sentido", e os meios que aplica são sua "técnica" (Weber, 1994, p. 38).

Repare-se que uma ação pode ser de natureza técnica, se ela estiver em função de outra, consistindo esta no fim e aquela exercendo o papel de meio. De qualquer maneira, considerada apenas nesses termos, a exposição weberiana em pouco contribui para a categorização qualitativa das propriedades do que pode ser um "agir técnico" e, por hora, se estamos em busca de uma suposta definição da técnica enquanto forma de ação social, nosso empreendimento, provisoriamente, terá que ficar em suspenso.

Para prosseguir nessa direção, será melhor que nos desviemos do conceito de "técnica" dirigindo nosso olhar ao conceito de "ação social". Para não nos alongarmos em um assunto que é por demais conhecido, vamos servir das definições sintéticas do próprio Weber, nas quais se pode ler: 
a ação social, como toda ação, pode ser determinada: (1) de modo racional referente a fins: por expectativas quanto ao comportamento de objetos do mundo exterior e de outras pessoas, utilizando essas expectativas como "condições" ou "meios" para alcançar fins próprios, ponderados e perseguidos racionalmente, com sucesso; (2) de modo racional referente a valores: pela crença consciente no valor ético, estético, religioso ou qualquer que seja sua interpretação - absoluto e inerente a determinado comportamento como tal, independentemente do resultado; (3) de modo afetivo, especialmente emocional: por afetos ou estados emocionais atuais; (4) de modo tradicional: por costume arraigado (Weber, 1994, p. 15).

Partindo das indicações de Weber, o primeiro resultado que podemos obter é a confirmação de um dado que já conhecemos. No pensamento weberiano, a técnica está presente em todas as formas de ação social, pois, seja buscando fins e valores, ou orientando-se pelos afetos e costumes, o indivíduo sempre precisa empregar meios para levar a termo sua conduta. Independente dos critérios que distinguem uma forma de ação de outra, a técnica é sempre uma propriedade da ação. No entanto, Weber não considerou a técnica como uma forma específica de agir, mas apenas como um “objeto alheio ao sentido" que atua em relação à ação como ocasião, resultado, estímulo ou obstáculo:

todo artefato, uma máquina, por exemplo, somente pode ser interpretado e compreendido a partir do sentido que a ação humana (com finalidades muito diversas) proporcionou (ou pretende proporcionar) a sua produção e utilização; sem o recurso a esse sentido permanecerá inteiramente incompreensível (Weber, 1994, p. 5).

A mesma conclusão pode ser obtida se reconstruímos o argumento de Weber de forma sistemática, como o faz Schluchter (apud Habermas, 1987, p. 363). Conforme lembra o intérprete, o primeiro tipo de ação social funciona para Weber como padrão ideal de evidência e os demais tipos de ação representam desvios em relação a esse modelo. Dessa forma, eles podem ser assim compreendidos: 
Máquinas Petrificadas: Max Weber e a sogiologia da tégnica

\begin{tabular}{|l|c|c|c|c|}
\hline $\begin{array}{l}\text { Tipos de ação segundo } \\
\text { graus decrescentes } \\
\text { de racionalidade }\end{array}$ & \multicolumn{4}{|c|}{$\begin{array}{c}\text { O sentido subjetivo compreende } \\
\text { os seguintes elementos }\end{array}$} \\
\hline & Meios & Fins & Valores & Consequências \\
Com relação a fins & $X$ & $X$ & $X$ & $X$ \\
Com relação a valores & X & X & $X$ & - \\
Afetiva & X & $X$ & - & - \\
Tradicional & X & - & - & - \\
\hline
\end{tabular}

Quadro 1. Tipologia da ação

O esquema não só deixa claro como os critérios de eleição de fins e valores e de escolha de meios e avaliação das consequências ajudam a diferenciar os tipos de ação, mas, tendo em vista nossos propósitos, ilustra perfeitamente como a questão do "meio" empregado é o único dos elementos que aparece em todas as formas do agir. Em última instância, o que poderíamos concluir, até aqui, é que o agir social e o agir técnico são sinônimos e, nessa medida, a conduta humana em sociedade é sempre uma atitude tecnológica, a ação social está sempre imbuída da instrumentalidade.

Mas, apesar dessa valiosa conclusão, o esquema de Weber nada nos diz a respeito do agir técnico como uma forma específica e diferenciada de ação. Disseminado em todas as formas de atividade social, o agir técnico não representa uma categoria sociológica com substância própria. No entanto, também aqui é preciso olhar com mais atenção. De acordo com Habermas, uma análise atenta revela que o tipo ideal weberiano de ação racional com relação a fins representa, em última instância, uma forma técnica de ação.

Arnold Gehlen chamou a atenção e, segundo me parece, de forma concludente para o fato de que existe uma conexão imanente entre a estrutura da técnica que conhecemos e a estrutura da ação racional dirigida a fins. Se entendemos o círculo funcional da ação controlada pelo êxito como a unificação da decisão racional e da ação instrumental, então podemos reconstruir a história da técnica sob o ponto de vista de uma objetivação gradual da ação racional teleológica (Habermas, 1994 , p. $\left.5^{1-2}\right)$.

Em sua própria teoria, Habermas reformulará o conceito weberiano de ação racional com relação a fins distinguindo-a da ação comunicativa (simbolicamente mediada). No esquema habermasiano, a ação racional teleológica cinde-se, por sua vez, em dois aspectos. Por um lado, a ação instrumental que, na base de regras técnicas 
apoiadas no saber empírico (previsibilidade), orienta-se pela busca do controle dos fatos ocorridos no mundo (realidade objetiva). De outro, a ação estratégica em que o agente orienta as possibilidades de êxito de sua conduta levando em consideração a mesma postura de outros indivíduos, ou seja, transferindo a lógica instrumental (ou técnica) para seus relacionamentos sociais (realidade intersubjetiva ou social).

Isso posto, a pergunta colocada no início deste tópico, a questão do agir técnico em Weber, já pode receber, assim, alguma resposta, ou melhor, uma dupla resposta. Por um lado, ele concebeu a técnica como um elemento presente em todas as formas de ação social, independentemente de suas diferenças qualitativas: qualquer que seja o tipo de ação, a técnica está presente como um elemento constante. Por outro lado, o exame crítico da tipologia weberiana da ação também mostra outra ideia: ao adotar a ação racional com relação a fins como padrão típico-ideal de análise, Weber a identifica, implicitamente, com um modelo técnico de agir. Nesse segundo caso, a ação técnica pode ser definida de forma substancial e positiva, pois, ao adotar a atitude individual do cálculo e da eficiência em sua relação com o mundo social, orientando-se pela adequação precisa de fins, meios e consequências (expurgando-a de qualquer elemento de valor, afeto ou costume), o indivíduo transfere a lógica técnica para o comportamento social. Agir tecnicamente, em Weber, significa orientar-se de forma racional em relação a fins. Ambas as definições não são contraditórias, pois o fato de que a instrumentalidade está presente em todas as formas de agir (sentido geral) não exclui a possibilidade de que ela se torne o móvel fundamental da ação (sentido específico).

\section{A RAGIONALIDADE TÉGNIGA}

É difícil para quem pensa em técnica não associá-la, muito rapidamente, à ideia de racionalidade. Adotar uma postura técnica parece, desde sempre, adotar uma atitude racional e, vice-versa. No entanto, técnica não é sinônimo de racionalidade e a ideia de instrumentalidade, em princípio, não se define pela de racionalidade. Contudo, sabemos que esses dois termos possuem uma especial "afinidade eletiva", o que nos coloca diante do imperativo de definir em que consiste essa relação. Para Weber, também essa ligação era direta, pois, segundo ele, "sempre que se apresentar uma "questão técnica', isso significa que existem dúvidas sobre os meios mais racionais" (1994, p. 38). Nossa atenção, na frase, recai em seu final e deixa-nos de imediato com algumas perguntas no ar, a saber, quando um meio é mais "racional" que outro? Ou ainda, o que faz com que um meio possa ser qualificado racional e outro não? Como medir a racionalidade do meio empregado? Enfim, o que a técnica tem a ver com a razão e a razão com a técnica? Adotando-se a ótica da sociologia weberiana, duas respostas emergem. 
Chamaremos a primeira, que parte diretamente do texto de Weber, de ótica interna, pois, nesse caso, a razão está sendo considerada no interior do contexto técnico. Mas, isso não nos deve levar a concluir, prematuramente, que toda técnica é racional. Se a técnica consiste, em princípio, nos meios disponíveis, dela não decorre necessariamente a racionalidade, a qual só faz sua aparição de forma externa, ou seja, como um critério de seleção e eleição de um dentre os meios disponíveis. Que Weber pensava dessa forma parece ser indicado claramente pelo fato de que ele aglutina os conceitos de "técnica" e de "razão" e só então nos oferece um novo conceito, o de técnica racional, definida como "uma aplicação de meios que, consciente e planejadamente, está orientada pela experiência e pela reflexão, e, em seu máximo de racionalidade, pelo pensamento científico" ( p. 38). Desse modo, devemos concluir que Weber está supondo que a racionalidade não é uma propriedade intrínseca da técnica, pois ele afirma que a técnica é racional quando a razão (que ele define como experiência e reflexão), por decisão (consciente) e cálculo (planejado) dos indivíduos, passa a orientá-la, ou seja, a técnica é racional quando guiada pela razão. Aliás, considerando-se a questão dessa maneira, não haveria motivo para não sustentar que também uma "técnica irracional" é possível, pois, em princípio, a razão não é critério único e exclusivo da escolha de meios e instrumentos. Mas, que outros critérios de escolha de meios sejam possíveis não retira o fato, óbvio e fundamental, de que, na modernidade, é a forma de saber científico que responde pela racionalidade legítima vigente, donde não ser surpresa nenhuma constatarmos que, também para Weber, o máximo de racionalidade na técnica resulta da aplicação e incorporação dos conhecimentos científicos, de modo que, quanto mais científica, tanto mais racional será a técnica.

Embora não se possa sustentar que a racionalidade é uma decorrência "necessária" da técnica (necessidade, lembram os filósofos, é algo que não pode deixar de ser), também é fato que a técnica possui especial afinidade eletiva com a razão, ou seja, a lógica da técnica e a lógica da razão tendem a atrair-se e reforçar-se mutuamente. Feita tal constatação, cabe-nos compreender qual é a natureza dessa relação, ou seja, o que acontece com a técnica quando guiada pela razão e, por outro lado, o que acontece com a razão quando inserida no contexto técnico? Desta ótica, não é mais da técnica racional que estamos falando, mas de outro fenômeno, ou seja, da racionalidade técnica. Weber irá apresentá-la da seguinte forma: "o critério de racionalidade para a técnica é, entre outros, também o famoso princípio do ‘esforço mínimo’: o resultado ótimo em comparação com os meios a serem aplicados" (p. 38).

Nestas poucas linhas, mais do que alongadas descrições históricas da invenção e criação de utensílios e máquinas, o que Weber oferece é uma plataforma sociológica que torna possível entender a lógica racional de funcionamento do desenvolvimento tecnológico. A técnica desenvolve uma dinâmica interna e própria quando se orienta 
pela racionalidade (em especial a racionalidade científica). Portanto, ela não responde apenas as demandas situadas exteriormente. Mesmo subordinada a fins, a técnica possui um critério interior de validade, ou sua "legalidade própria" (Eigengesetzlickheit), empregando aqui a terminologia de Weber. Em sua constituição intrínseca, a racionalidade técnica significa que a pluralidade de meios disponíveis para a realização de um fim (que já está dado) pode ser avaliada a partir dela mesma. Ao apontar para a determinação interna da técnica, Weber não eliminou a importância dos fins ou objetivos para situar o entendimento do elemento técnico. Mas, o objetivo delimita apenas os meios disponíveis, sendo a escolha comparativa desses meios orientada pela própria lógica racional. A essência do processo está localizada na eficácia; seria tanto mais racional aquele meio ou instrumento (técnica) que produzir o resultado desejado com o menor dispêndio de recursos.

Assim considerado, o conceito weberiano de racionalidade técnica é essencialmente interno, quer dizer, entende a racionalidade técnica como uma decorrência lógica da articulação entre razão e técnica, técnica e razão. Mas, partindo do sistema global do pensamento weberiano, também podemos pensar o tema de forma mais ampla, considerando a racionalidade técnica na sua relação com o âmbito exterior, ou seja, com o próprio mundo. Que tipo de relação entre o homem e o mundo decorre da racionalidade técnica?

Para compreender a racionalidade técnica sob a ótica externa precisamos recorrer não aos textos, mas aos pressupostos globais do pensamento de Weber. Esse exercício é possível exatamente porque a questão da racionalidade e da racionalização é concebida pela maioria dos especialistas (cf. Schluchter, 1981) como o eixo de sua teoria. Assim, faz todo sentido indagar o que a "racionalidade técnica", em um âmbito específico, tem a ver com a "racionalidade" em si mesma, no sentido geral do termo. A indagação pode ser traduzida na forma da seguinte pergunta: de que tipo é a racionalidade que permeia a técnica moderna? Reconstruída de forma sistemática, a pergunta recebe uma resposta no quadro abaixo, elaborado por Wolfgang Schluchter (1989, p. 101). 
MÁQuinas Petrificadas: Max Weber e a sogiologia dA técnica

\begin{tabular}{|l|c|c|}
\hline Direção do interesse & Teórico & Prático \\
\hline Esfera & $\begin{array}{c}\text { Racionalização causal } \\
\text { Experiência } \\
\text { Racionalismo científico }\end{array}$ & $\begin{array}{c}\text { Racionalização instrumental } \\
\text { Tecnologia } \\
\text { Racionalismo técnico }\end{array}$ \\
\hline Extramundana & $\begin{array}{c}\text { Racionalização intelectual } \\
\text { Metafísica }\end{array}$ & $\begin{array}{c}\text { Racionalização valorativa } \\
\text { Ética } \\
\text { Racionalismo metafísico }\end{array}$ \\
\hline
\end{tabular}

Quadro 2. Formas fundamentais de racionalização e racionalismo

O esquema revela que a técnica implica uma forma muito específica de racionalidade, uma racionalidade prática de caráter intramundano. Mas, o que isso significa? Antes de responder, precisamos esclarecer o significado dos conceitos acima empregados. Ambos representam duas categorias-chave que orientam a sociologia comparativa dos múltiplos processos de racionalização cultural elaborada por Weber. Através dos conceitos de racionalidade teórica e prática ele desejava explicar os rumos diferenciados que a racionalização seguiu no Oriente e no Ocidente. De acordo com a explicação fornecida na Enleitung (A psicologia social das religiões mundiais), os conceitos podem ser assim definidos:

[racionalismo] significa uma coisa, se pensarmos no tipo de racionalização que o pensador sistemático realiza sobre a imagem do mundo: um domínio cada vez mais teórico da realidade (theoretische Berherrschung der Realität) por meio de conceitos cada vez mais precisos e abstratos. O racionalismo significa outra coisa, se pensarmos na realização metódica de um fim, precisamente dado e prático, por meio de um cálculo cada vez mais preciso dos meios adequados. Esses tipos de racionalismo são muito diferentes, apesar do fato de que, em última instância, estão inseparavelmente juntos (Weber, 1982a, p. 337, grifos meus).

Diferenciados de acordo com sua orientação para o mundo secular (intramundano), ou para a direção contrária (extramundana), as diferentes formas de racionalidade são as responsáveis por diferentes posturas do homem (e das sociedades) perante a realidade. Em sua dimensão cognitiva, ela pode ser de natureza metafísica ou científica e, na dimensão pragmática, ética ou técnica. Vista a partir de tal esquema, a modernidade é fruto da transição da cosmovisão ético-metafísica para uma visão científico-tecnológica do mundo. A ciência e a técnica têm em comum o fato de que ambas 
são voltadas para a realidade secular, representando a primeira uma tentativa de explicação teórica da realidade, e a segunda a busca de seu controle sistemático. Nos moldes aqui propostos, o que aprendemos associando o tema da racionalidade ao tema da técnica não é apenas, como já fizemos antes, a compreensão da racionalidade intrínseca dos instrumentos técnicos. Sem negar essa aquisição teórica, o que o novo esquema permite ver é também que a racionalidade técnica é uma forma de relacionamento do homem com o mundo. A racionalidade prática e intramundana da técnica implica uma forma determinada e específica de relação com a natureza, com os demais indivíduos e com minha própria subjetividade, todos tornados, agora, ob-jetos, ou seja, entes intramundanos situados à disposição da vontade humana.

A racionalização moderna assenta-se sobre essa base, mas ela é apenas uma via possível, dentre outras. Tivesse preponderado entre nós a racionalidade teórica e extramundana vigente no misticismo das religiões da Índia, por exemplo, o homem seria concebido como parte de um cosmos ordenado, fixo e imutável (concepção metafísica) a que ele se submete mediante seu comportamento ético. A racionalização ocidental ou moderna, a racionalidade prático-intramundana e a racionalidade técnica, perceberá o leitor, são apenas variações de uma realidade que, no fundo, é a mesma. Daí que já seja perfeitamente possível dizer que, em Weber, modernidade e técnica tocam-se e que a teoria weberiana da racionalização possui na técnica um de seus vetores centrais. Desenvolver tal ideia será o assunto de nosso próximo tópico.

\section{A ragionalização tÉG Nica}

O conceito de "racionalidade técnica" aponta para um fenômeno estrutural que permeia e subjaz ao campo da técnica, ou seja, ao campo dos meios e instrumentos. Diferentemente, falar de "racionalização técnica" implica em assumir um ponto de vista dinâmico, mostrando de que forma a racionalidade técnica desdobra-se de forma processual, ou seja, enquanto desenvolvimento histórico e social. Em Max Weber, podemos localizar duas formas diferentes de análise da racionalização técnica. Em primeiro lugar, trata-se de demonstrar como a lógica racional implícita no mundo da tecnologia atua como força que impulsiona suas transformações e desenvolvimentos. Nesse âmbito mais restrito, racionalização técnica torna-se sinônima de "racionalização da técnica", mostrando como, alicerçada na razão, a técnica se modifica e evolui com o tempo. Mas, o processo também pode ser compreendido de forma mais ampla fazendo-nos pensar a ligação da técnica com a sociedade. Em tal caso, a racionalização técnica abrange o processo de preponderância da racionalidade técnica sobre as outras formas de ação social e sua generalização no conjunto do tecido social; a racionalização técnica é si- 
MÁQuinas Petrificadas: Max Weber e a sogiologia dA técnica

nônima de "racionalização técnica do social". Vejamos de que forma Weber entendia cada um desses processos.

\subsection{A racionalização da tÉGnica}

No âmbito mais específico e delimitado do desenvolvimento tecnológico, algumas das investigações empíricas de Weber surpreendem pela riqueza de seus detalhes. No texto História geral da economia, por exemplo, ele descreve em minúcias o processo de maquinização da técnica econômica moderna. Inicialmente, o pensador chama a atenção para o papel fundamental da fábrica em todo esse processo, pois ela é o locus em que empresários, trabalhadores, fontes de energia, processos de trabalho e máquinas puderam ser reunidos. Foi no espaço da fábrica que os aparelhos evoluíram até tornarem-se máquinas: "a diferença verifica-se no fato de que os aparelhos estão a serviço do homem, enquanto que na máquina moderna ocorre precisamente o contrário" (Weber, 1980a, p. 139). Weber data com precisão o processo de surgimento das fábricas (a mais antiga seria de 1719 e a manufatura de lã é de 1738) e destaca que um fator decisivo para a racionalização e mecanização do trabalho foi o desenvolvimento da manufatura de algodão ao longo do século xvıı. É nesse setor da economia que se desenvolveu o tear, o uso do fuso, novas fontes de matérias primas (o carvão e o ferro) e, finalmente, a invenção da máquina a vapor.

Conforme a explicação de Weber, a mecanização do processo produtivo - elemento central do desenvolvimento técnico da era moderna - apoiou-se em três elementos centrais. O primeiro foi o uso de novas matérias primas, pois "mediante o carvão e o ferro conseguiu-se uma independência da técnica e, com isso, a possibilidade de lucro, com referência aos limites estabelecidos pelos materiais do mundo orgânico" (1980a, p. 1411), o que ocorreu porque as fontes de energia não dependiam mais da força animal ou do crescimento das árvores. Para ele, o ferro teria sido o fator mais importante para o desenvolvimento do capitalismo e não saberíamos o que seria do desenvolvimento europeu sem ele. Em segundo lugar, "a mecanização do processo produtivo, mediante a máquina a vapor, libertou a produção das barreiras orgânicas do trabalho" (1980a, p.141). Embora a presença do homem continue a ser indispensável, o uso de máquinas diminuiu a quantidade de mão-de-obra necessária. O terceiro e último fator foi a associação entre conhecimento e processo produtivo. Libertando-se da tradição, "tal produção entra em íntimo contato com a inteligência livre" (p.141). O rompimento das barreiras tradicionais da livre investigação foi acentuada no momento em que a técnica associa-se com a esfera científica, levando "o capitalismo até um nível de pleno desenvolvimento" (p. 1411). A aplicação do conhecimento especializado no processo produtivo exerceu um papel vital no desenvolvimento tecnológico. "A tendência à 
racionalização da técnica e da economia, com o fim de diminuir os preços, em proporção aos custos, deu lugar, durante o século xviı, a uma corrida na busca de inventos" (p. 144). Diferentemente do inventor pré-capitalista (cujas descobertas ocorriam de forma empírica e casual), a inventividade torna-se um fator constante da época moderna, orientando-se pela busca contínua do barateamento da produção.

As observações acima revelam que Weber viu nos artefatos, inventos e máquinas dos tempos atuais muito mais do que um desenvolvimento quantitativo e intensivo de novas tecnologias. Entre a técnica atual e a técnica dos tempos pregressos situa-se uma ruptura qualitativa. Uma tal descontinuidade permite que falemos, então, da técnica moderna. A sua nota central e específica é a independência da técnica em relação ao ciclo natural e humano. Opera-se aqui uma inversão, pois a técnica pré-moderna ainda opera dentro de claros limites dados no mundo natural e humano, enquanto nos tempos modernos esse limite se rompe, sendo homem e natureza funcionalizados pela técnica. A noção de "independência” do complexo técnico aponta não apenas na direção do caráter sistêmico da técnica no contexto da modernidade (demonstrando seu caráter autopoiético), como também deixa entrever uma importante contradição ou patologia social de nossa época, o alheamento (Entfremdung) dos meios, criados pelo homem, de seu próprio criador. Além de apontar para a autonomização da técnica, Weber também captou com notável antecipação um fenômeno que seria largamente discutido apenas depois da Segunda Grande Guerra, a associação entre técnica e ciência (tecnociência). Na visão de Weber, técnica e ciência caminhavam na mesma direção e repousavam sobre uma base comum: "uma ciência racional e uma técnica racional foram coisas desconhecidas para aquelas culturas [não ocidentais]" (Weber, 1980a, p. 146). Quando associada à ciência, como havia dito Weber, a técnica adquire sua máxima racionalidade.

\subsection{A RaGionalizaÇÃo tÉGnica do AGir SoGial}

Em um sentido mais amplo, a racionalização técnica também é concebida por Weber como um contínuo processo de tecnificação da vida social. Neste tópico procuro demonstrar que este processo foi pensado por Weber em três planos distintos: o individual, o cultural e o social. Ou seja, o predomínio crescente da racionalidade técnica ocorre no nível da ação social, desdobrando-se no plano da cultura e das estruturas sociais.

No contexto da ação social, o autor descreveu o processo de racionalização da seguinte forma:

um componente essencial da "racionalização" da ação é a substituição da submissão interna ao costume habitual pela adaptação planejada a determinadas si- 
tuações de interesses. Esse processo, no entanto, não esgota o conceito de "racionalização" da ação. Pois pode suceder que essa ocorra, de maneira positiva, em direção a uma racionalização consciente de valores, porém, de maneira negativa, às custas não apenas do costume mas igualmente da ação afetiva e, finalmente, também em direção à ação puramente racional referente a fins e não crente em valores, às custas da ação racional em relação a valores (Weber, 1994, p. 19).

Vemos aqui que racionalização da ação significa a predominância contínua e crescente da ação racional com relação a fins sobre as outras formas do agir social. Em nossa releitura, demonstramos que essa forma de ação, de caráter instrumental, é essencialmente técnica, daí podemos concluir que a expansão da racionalidade com relação a fins é sinônimo de racionalização técnica, ou posto de outra forma, a racionalização da ação é uma forma de racionalização técnica.

Os vínculos que ligam a racionalização (em geral) e a racionalização técnica (em particular) também podem ser confirmados, se observamos a natureza do conceito weberiano de racionalidade. Neste particular, Habermas nos oferece o seguinte esclarecimento. "Weber parte de um conceito amplo de 'técnica' para demonstrar que o aspecto de emprego regulado de meios é, em um 'sentido muito abstrato', relevante para a racionalidade do comportamento" (1987, p. 228). Mais a frente, esclarece ainda Habermas que "esse conceito amplo de 'técnica' e de 'racionalização dos meios' é restringido por Weber especificando os meios" (p. 229). O que Habermas nos faz perceber é que, assim como o conceito de ação, também o conceito weberiano de racionalidade toma o modo técnico de pensar e agir como seu substrato, o que significa que o conceito geral de racionalidade empregado por Weber toma a racionalidade técnica como seu modelo. Por isso é forçoso concluir, mais uma vez, que racionalização e racionalização técnica são sinônimas.

Para explicar a dinâmica do processo de racionalização da ação, Weber efetuou extensas pesquisas de caráter empírico. Adotando uma perspectiva histórico-comparativa, ele demonstrou o processo de gênese e também a especificidade do racionalismo ocidental. A análise foi complementada com a pesquisa das formas racionalizadas da vida moderna, tarefa que Weber desenvolve, especialmente, em Economia e sociedade. Juntos, ambos os projetos de pesquisa oferecem uma explanação de como o processo de racionalização da ação pode ser compreendido, no nível cultural, mediante o estudo da gênese (perspectiva histórico-diacrônica) e, no nível social, mediante o estudo de sua materialização institucional nas ordens de vida modernas (perspectiva sociológico-estrutural). Na perspectiva aqui proposta, cada um destes processos pode ser relido como uma forma diferenciada de análise da trajetória de tecnificação da vida social. 
No âmbito cultural, a preocupação central de Weber foi determinar "a peculiaridade específica do racionalismo ocidental e, dentro deste moderno racionalismo ocidental, a de esclarecer a sua origem" (Weber, 1996, p. 11). A racionalidade não era uma exclusividade do Ocidente e seguiu caminhos histórica e culturamente diferenciados. No Oriente, o misticismo indiano engendrou o racionalismo da fuga do mundo, enquanto o pragmatismo chinês determinou a gênese do racionalismo da acomodação ao mundo. Foi somente no Ocidente que uma combinação particular de fatores (entre eles, o desencantamento do mundo) produziu as condições para o surgimento de uma forma muito particular de racionalização: o racionalismo da dominação do mundo. Ao comparar o caso protestante com o caso da China, ele assim se expressou:

O “racionalismo" (...) impregna o espírito de ambas as éticas. Só que unicamente a ética racional purista, orientada ao supramundano, levou a término o racionalismo econômico intramundano (...) O racionalismo confuciano significava adaptação racional ao mundo (rationale Anpassung an die Welt). O racionalismo puritano, dominio racional do mundo (rationale Beherrschung der Welt) (Weber, 1991, p. 524).

O racionalismo da dominação do mundo é, pois, a marca específica da racionalização ocidental. Retomando o conceito com bastante atenção vamos perceber que também ele se sustenta sobre a racionalidade técnica. Mais acima tínhamos demonstrado que a racionalidade técnica comporta uma forma determinada e específica de relação do homem com o mundo, isto é, um racionalismo prático de caráter intramundano. Ora, o conceito de racionalismo da dominação do mundo possui exatamente as mesmas características, pois ele é o resultado da influência da cosmovisão protestante sobre a cultura ocidental, com sua ética de caráter prático (ascetismo) e sua orientação para o mundo através do trabalho metódico e racional. Falar de gênese do racionalismo da dominação significa, assim, outra forma de descrever o conjunto de fatores contingentes que produziram a preponderância cultural da racionalidade técnica no mundo moderno. O racionalismo da dominação traduz o processo de gênese cultural e predominância crescente do agir técnico em escala ocidental.

Weber se preocupou não apenas com a origem histórica desse processo, mas também deteve-se amplamente na descrição de como o racionalismo da dominação do mundo, com seu caráter prático e intramundano (racionalidade técnica) estava presente em todos os setores da vida social moderna: economia, política, direito, ciência, arte etc. Vista desse ângulo, a preocupação de Weber foi mostrar a materialização sócio-institucional do racionalismo. A descrição mais extensa do processo pode ser encontrada em Economia e sociedade nos capítulos em que o autor trata da economia, da 
política, do direito, da religião etc. No entanto, há ainda uma visão mais condensada de suas teses no texto Consideração intermediária, escrito no qual Weber (1982b) postula que as ordens sociais de vida do mundo moderno desprendem-se da orientação religiosa anterior e, uma vez autonomizadas, passam a operar segundo sua legalidade própria (Eigengesetzlichkeit). Passando em revista a esfera econômica, política, artística, erótica e científica, Weber argumentava que, em cada uma delas, o indivíduo encontra-se diante de sistemas sociais operando por seus próprios mecanismos, independentemente dos fins ou objetivos que os indivíduos queiram conferir-lhes. Nas estruturas sociais modernas, o agir social em relação a valores foi completamente suplantado pelo agir racional com relação a fins (pelo agir técnico). Portanto, a tese da autonomização das esferas sociais da vida moderna indica claramente a inversão entre meios e fins. As esferas econômica, política, estética, erótica e científica deixaram de ser instrumentos colocados a serviço das intenções humanas para inverterem o processo. Congeladas em seus processos internos, as ordens de vida moderna transformam os indivíduos em seus próprios fins. Essa é também uma outra maneira de compreender a tecnificação da vida social, pois os meios técnicos tornaram-se o fator preponderante e passaram a plasmar por inteiro a lógica de funcionamento do mundo moderno.

A transformação da racionalidade de fins em racionalidade de meios já está colocada no mais conhecido trabalho de Weber (2004), A ética protestante e o espírito do capitalismo, escrito em duas partes, entre 1904 e 1905. Na obra, seu objetivo precípuo era investigar de que modo os impulsos práticos de ação (moral) provenientes das seitas do protestantismo ascético colaboraram na gênese do "espírito" do capitalismo. Em seu ponto de partida, o estímulo para uma vida ordenada pelo trabalho e pela busca da riqueza como centro da existência teve suas raízes em motivações religiosas, ou seja, desempenhando a religião a função de meta e o trabalho, de instrumento. Para Weber, a secularização desse modo de vida influiu diretamente na gênese do moderno tipo de homem especializado e do homem de negócios, ou seja, o puritanismo engendrou o homo oeconomicus moderno, tanto o empresário quando o sóbrio trabalhador das fábricas. Mas, no processo de deslocamento das motivações religiosas, o trabalho ordenado deixou de ser um instrumento a serviço de metas religiosas para converter-se em fim imanente, que existe e subsiste por si mesmo. "Atualmente a ordem econômica capitalista é um imenso cosmos em que o indivíduo já nasce dentro, e para ele, ao menos enquanto indivíduo, se dá como um fato, uma crosta que ele não pode alterar e dentro da qual tem que viver" (Weber, 1994, p. 48, grifo meu). Mais à frente, a mesma ideia é repetida nos seguintes termos: "a ideia da obrigação do ser humano para com a propriedade que lhe foi confiada, à qual se sujeita como prestimoso administrador ou mesmo como 'máquina de fazer dinheiro', estende-se por sobre a vida feito uma crosta de gelo" (p. 55, grifo meu). Outra metáfora tem um sabor ainda mais técnico: "ninguém 
sabe ainda quem no futuro vai viver sob essa crosta e, se ao cabo desse desenvolvimento monstro, hão de surgir profetas inteiramente novos, ou um vigoroso ressurgir de velhas ideias e antigos ideais, ou - se nem uma coisa nem outra - o que vai restar não será uma petrificação chinesa [ou melhor, mecanizada]" (p. 166, grifo meu). Por fim, naquela que se tornará uma das mais célebres metáforas da sociologia weberiana, ele definiu a "congelada" racionalidade instrumental do trabalho, agora convertida em fim, como uma jaula de ferro: "Na opinião de Baxter, o cuidado com os bens exteriores devia pesar sobre os ombros de seu santo apenas 'qual leve manto de que se pudesse despir a qualquer momento'. Quis o destino, porém, que o manto virasse uma rija crosta de aço" (p. 165, grifo meu).

Diagnóstico semelhante ao anterior foi também apontado por Weber na esfera da política. Desde seus primeiros escritos políticos, ele chamou a atenção para o vazio de liderança após o período de Bismarck. "Qual foi então o legado de Bismarck no que aqui nos interessa? Ele deixou atrás de si uma nação sem qualquer sofisticação política" (1980b, p. 14). Essa situação abriu espaço para o predomínio da burocracia na condução dos negócios do Estado. "Desde a renúncia do príncipe Bismarck, a Alemanha tem sido governada por 'burocratas', resultando a eliminação de todo talento político" (p. 27). Contudo, o corpo burocrático deveria ter como tarefa apenas viabilizar os meios em função das decisões políticas, pois sua característica era a especialização e o treinamento racionais. Portanto, o predomínio da burocracia sobre a liderança significava mais um sintoma da inversão entre meios e fins. Weber julgava o processo de burocratização como um processo amplo que, passando da empresa à igreja e aos partidos, chegava inevitavelmente até o Estado: “Em um Estado moderno necessária e inevitavelmente a burocracia realmente governa, pois o poder não é exercido por discursos parlamentares nem por proclamações monárquicas, mas através da rotina da administração" (198ob, p. 16). Apesar de apostar na renovação do parlamento como um mecanismo suscetível de forjar líderes políticos capazes de fazerem frente ao predomínio dos burocratas, Weber enxergava o fenômeno da burocratização como um processo inevitável. Segundo sua fórmula, "o futuro pertence à burocratização" (p. 23), pois em contraste com as formas anteriores, a burocracia moderna possui uma natureza que a torna "à prova de fuga": a especialização e o treinamento racionais. O processo de tecnificação burocrática da vida política foi descrito pelo pensador em termos nada animadores:

Uma máquina inanimada é a mente (mind) concretizada. Somente esse fato proporciona à máquina o poder de forçar os homens a operá-la, e o poder de dominar suas vidas de trabalho diário tão completamente como ocorre em realidade na fábrica. A inteligência concretizada é também uma máquina animada, a da or- 
ganização burocrática (...) Juntamente com a máquina inanimada, a inteligência concretizada ocupa-se em construir a concha da servidão que os homens serão talvez forçados a habitar algum dia, tão impotentes quanto os felás do Egito antigo (Weber, 1994, p. 25).

\section{Conclusão}

Martin Heidegger (cf. 2007), em texto no qual busca pela própria essência da técnica, aponta que as definições usuais sobre este tema tendem a concebê-la como um meio a serviço do agir humano. Ao definir a técnica a partir da categoria de "meio" e situá-la como elemento permanente da ação social, a formulação weberiana também pode ser concebida, na mesma direção, como instrumental e antropológica. Assim, apesar da precisão terminológica que lhe é peculiar, e do aprofundamento especialmente útil de categorias como técnica, racionalidade técnica e ação técnica, entre outras, não é especialmente no campo das definições lógicas que reside a originalidade da reflexão weberiana. A menção a Heidegger está aí para indicar que, a esse respeito, Weber apenas segue um caminho solidamente traçado na tradição filosófica ocidental.

Mas, um juízo semelhante não seria justo quando passamos ao registro específico da sociologia. Desse ângulo, Weber possui méritos muito maiores do que de mero precursor ou fundador, como se o seu principal valor consistisse apenas em abrir caminho. Ainda que incipiente, a validade da sociologia weberiana da técnica parece-me residir na sua capacidade de articular diferentes planos de análise. A começar pelo plano da ação social, ponto de partida de sua ótica sociológica, em que ele aponta não só para o fato de que sempre existe um elemento técnico presente na ação social, mas também permite inferir as propriedades do agir técnico como forma diferenciada de ação social (atitude técnica). Em um segundo plano, Weber possui também uma análise social da "tecnologia", apontando para as propriedades específicas da técnica e sua racionalidade e descrevendo com precisão a evolução tecnológica do tempo presente. No entanto, ele realiza essa tarefa sem limitá-la a esse ponto. Em sua análise, a própria modernidade vê-se atravessada pela atitude intramundana de dominação do mundo, ou seja, por uma racionalidade técnica que passa a gerir o espírito de todas as demais instituições sociais. Em síntese, o pensar weberiano move-se do nível da ação para o nível estrutural e, no processo, ele nos permite pensar (1) as propriedades do agir técnico, (2) a especificidade da racionalização das técnicas modernas e, por fim, (3) a racionalização técnica da modernidade. Em Weber, podemos encontrar, diferenciadas e articuladas, uma teoria da "ação técnica", uma específica "sociologia da técnica" e, por fim, uma "sociologia da modernidade técnica". Nessa medida, ele permanece um mo- 
delo paradigmático para quem, sem ceder a nenhuma forma de ingênuo determinismo tecnológico, entende que a técnica é um dos elementos centrais para definir a vida social contemporânea.

Ao articular a temática da técnica com a questão da racionalidade, os analistas observam que a sociologia de Weber comporta uma contradição interna. Para Herbert Marcuse (cf. 1972), a definição weberiana da racionalidade moderna toma emprestado seu conteúdo da racionalidade capitalista e, como tal, é uma apologia desse modo de produção. Despida do tom conspiratório que lhe confere Marcuse, a tese reaparece em Habermas (cf. 1987) que nota que, de fato, a teoria weberiana da racionalização não consegue escapar do predomínio monológico da racionalidade instrumental. As críticas formuladas pelos teóricos da Escola de Frankfurt caminham na mesma direção e apontam para um evidente déficit normativo da teoria weberiana. Embora apontando para o predomínio da lógica técnico-instrumental como a patologia central da ordem moderna (perda de sentido e perda de liberdade), Weber serve-se dos mesmos instrumentos que critica para formular sua teoria. É por esta razão que, podemos assim supor, não resta para Weber outra alternativa a não ser concluir pela inevitabilidade do processo de burocratização universal, sendo a responsabilidade individual pelo próprio destino o único espaço de liberdade ainda possível. Weber sentiu o peso das máquinas petrificadas sobre a nossa vida, mas não pôde vislumbrar, na própria realidade, formas alternativas de pensar e de viver. Apesar disso, seu legado deixa-nos valiosas contribuições que, retomadas, convidam para serem atualizadas e superadas, pois ele mesmo tinha consciência de que "quem pretende servir à ciência deve resignar-se a tal destino", afinal, "não só nosso destino, mas também nosso objetivo é o de vermosnos, um dia, ultrapassados. Não nos é possível concluir um trabalho sem esperar, ao mesmo tempo, que outros avancem ainda mais. E, em princípio, esse progresso prolongar-se-á ao infinito" (Weber, 1967, p. 29).A

Carlos Eduardo SELL Professor Doutor do Departamento de Sociologia Política, Universidade Federal de Santa Catarina, Brasil. sell@cfh.ufsc.br 


\title{
Máquinas petrifigadas: Max Weber e a sogiologia da tégnica
}

\begin{abstract}
What is the role of technology in the thought of Max Weber? From the examination of the categories of technical, technical action and technical rationality, the paper demonstrates that Weber's reflections on technology moves in two dimensions - dealing, in one dimension, with understanding of the specificity of technology as a social phenomenon, and, in the other, more broadly with the role of science and technology in modernity. Based on his reflections in these two dimensions, Weber examined the rationalization of machinery in the context of the emergence of the modern era and, at the same time, described the process of rationalization as a broad cultural process of mechanization of action and dominance of technical rationality on the whole of social life.
\end{abstract}

KeYwords $・$ Max Weber. Technology. Rationality. Rationalization. Technological modernity.

\section{REFERÊNGIAS BIBLIOGRÁFIGAS}

Brüseke, F. J. A modernidade técnica. Revista Brasileira de Ciências Sociais, 17, 49, p. 135-44, 2002.

Coнn, G. (Org.). Weber. 5. ed. São Paulo: Ática, 1991.

Freund, J. Sociologia de Max Weber. 4. ed. Rio de Janeiro: Forense Universitária, 1987.

Goffi, J. Y. La philosophie de la technique. Paris: PUF, 1988.

HABERMAS, J. Teoria da la acción comunicativa: racionalidad de la acción y racionalización social. Madrid:

Taurus, 1987 .

Técnica e ciência como ideologia. Lisboa: Edições 70, 1994.

Heidegger, M. A questão da técnica. Scientiae Studia, 5, 3, p. 357-98, 2007.

Marcuse, H. Industrialization and capitalism. In: Stammer, O. (Ed.). Max Weber and sociology today.

NewYork: Harper \& Row, 1972. p. 133-51.

Schlughter, W. The rise of western rationalism: Max Weber's development history. Berkeley: California Press, 1981.

. Rationalism, religion and domination. Berkeley: California Press, 1989.

Stammer, O. (Ed.). Max Weber and sociology today. NewYork: Harper \& Row, 1972.

Weber, M. Ciência e política: duas vocações. São Paulo: Cultrix, 1967. História geral da economia. 2. ed. São Paulo: Abril Cultural, 1980a. p. 121-78. (Os Pensadores). Parlamento e governo na Alemanha reordenada. 2. ed. São Paulo: Abril Cultural, 1980b. p. 1-85. (Os Pensadores). . Ensaios de sociologia. 5. Ed. Rio de Janeiro: Guanabara, 1982. A psicologia social das religiões mundiais. In: . Ensaios de sociologia. 5 . ed. Rio de Janeiro: Guanabara, 1982a. p. 3o9-4,6. . Rejeições religiosas do mundo e suas direções (Zwischenbetrachtung). In: Ensaios de sociologia. 5. ed. Rio de Janeiro: Guanabara, 1982b. p. 371-4,10.

. Religião e racionalidade econômica. In: Сонn, G. (Org.). Weber. 5. ed. São Paulo: Ática, 1991. p. $14,2-59$.

. Economia e sociedade. 3. ed. Brasília: UnB, 1994. v. 1. . Introdução (Vorbemerkung). In: A ética protestante e o espírito do capitalismo. 11. ed. São Paulo:

Pioneira, 1996. p. 1-18. A ética protestante e o "espírito" do capitalismo. São Paulo: Companhia das Letras, 2004. 